\title{
IMPLEMENTASI KOMBINASI 3IC Tools SEBAGAI PENENTU OPTIMASI PENGENDALIAN PERSEDIAAN MINYAK GORENG
}

\author{
Hery Purnomo dan Lilia Pasca Riani \\ Fakultas Ekonomi, Universitas Nusantara PGRI Kediri \\ Email: herypurnomo@unpkediri.ac.id dan liliapasca@unpkediri.ac.id
}

\begin{abstract}
The purpose of this study were: 1) To analyze the brands of cooking oil that entered the class A classification using the ABC method, 2). To maximize safety stock that must be provided, and 3) determine the most Reorder Point for cooking oil products that enter in class A. This research is a descriptive research with quantitative approach. Data collection uses observation, and interview studies. In data analysis techniques, the authors do it in three stages, namely the first stage of $\mathrm{ABC}$ analysis to identify products in class $\mathrm{A}, \mathrm{B}$, or $\mathrm{C}$; the second stage calculates safety stock for cooking oil products that enter class A; and the third stage determines the size of the Reorder Point. Then taken the conclusion according to the purpose of research. The results of this research show that from 86 types of brands and packaging of cooking oil, there are 28 packs that belong to category A, with the highest safety stock calculation is on Sugarap brand oil of Reffil 2 Liter, and Reorder Point at most on brand oil of Rosebrand Packaging Reffil 1 liter.
\end{abstract}

Keywords: Retail, Cooking Oil, Inventory Control, ABC Method, Safety Stock, Reorder Point

\begin{abstract}
Abstrak: Tujuan penelitian ini adalah: 1) Untuk menganalisis merk minyak goreng yang masuk klasifikasi kelas A menggunakan metode ABC, 2). Untuk menganasilis safety stock paling besar yang harus disediakan, dan 3) menentukan Reorder Point paling banyak untuk produk minyak goreng yang masuk pada kelas A. Penelitian ini merupakan jenis penelitian deskriptif dengan pendekatan kuantitatif. Pengumpulan data menggunakan studi observasi, dan wawancara, Dalam teknik analisis data, penulis lakukan dengan tiga tahap, yakni tahap pertama analisis $\mathrm{ABC}$ untuk mengkalifikasikan produk pada kelas $\mathrm{A}, \mathrm{B}$, atau $\mathrm{C}$; tahap kedua menghitung safety stock pada produk minyak goreng yang masuk kelas A; dan tahap ketiga menentukan besarnya Reorder Point. Kemudian diambil kesimpulan sesuai tujuan penelitian. Hasil penelitian ini menunjukkan dari 86 jenis merek dan kemasan minyak goreng, terdapat 28 kemasan yang masuk kategori kelas A, dengan perhitungan safety stock terbesar ada pada minyak goreng merek Sedaap Kemasan Reffil 2 Liter, dan Reorder Point paling banyak pada minyak goreng merek Rosebrand Kemasan Reffil 1 Liter.
\end{abstract}

Kata Kunci: Retail, Minyak Goreng, Pengendalian Persediaan, Metode ABC, Safety Stock, Reorder Point

\section{PENDAHULUAN}

Retail modern seperti Toserba, Swalayan, dan Supermarket dewasa ini mulai berkembang pesat seiring dengan perkembangan teknologi tepat guna berbiaya murah yang beredar di masyarakat, antara lain teknologi komputerisasi pencatatan produk-produk di gudang hingga teknologi aplikasi multimedia berbasis jaringan sosial. Hal tersebut 
memunculkan persaingan yang semakin ketat antar retailer modern, antara lain dari segi penentuan harga, kualitas produk yang dijual, hingga pelayanannya, dan variasi produk. Retailer dituntut untuk menyediakan sebanyak banyaknya variasi untuk satu macam produk saja, sehingga konsumen dapat memilih dengan leluasa dengan memperbandingkan harga dan kualitas produk dengan merek lain namun tetap dalam satu retailer. Dengan kata lain, persediaan barang dagang untuk retailer sangat penting, Menurut Ishak (2010) persediaan adalah sumber daya menganggur (Idle Resource) yang belum digunakan karena menunggu proses yang lebih lanjut, proses lebih lanjut disini berupa kegiatan produksi. Sejalan dengan itu menurut Martani et al., (2012) persediaan merupakan salah satu aset yang penting bagi entitatas baik bagi perusahaan ritel, manufaktur, jasa, maupun entitas lainnya.

Semakin banyak variasi untuk satu jenis produk, menyebabkan semakin banyak alokasi investasi untuk menjaga jangan sampai satu produk mengalami stock out, terutama untuk jenis produk konsumsi sehari-hari, antara lain produk perlengkapan mandi, produk kecantikan, dan bahan-bahan makanan. Pengelola retailer harus jeli dalam menentukan jenis produk mana yang harus diadakan persediaan yang banyak maupun sedikit, jenis produk yang paling banyak atau sering dibeli oleh konsumen, jenis produk yang memiliki kontribusi paling tinggi dalam proyeksi laba, maupun produk yang margin laba nya rendah. Begitu juga dengan kombinasinya, semisal jenis produk yang paling banyak atau sering dibeli oleh konsumen namun margin labanya rendah, atau produk yang jarang dibeli namun margin labanya besar untuk perusahaan.

Peretail harus mampu mengelola barang dagangannya dengan meningkatkan kegiatan pengendalian persediaan barang dagangan, agar target laba perusahaan tercapai sekaligun dapat menyeimbangkan antara persediaan barang yang ada digudang dengan permintaan konsumen. Secara teori terdapat banyak metode yang dapat diimplementasikan terkait pengendalian persediaan (Inventory Control) barang dagangan, yakni analisis ABC, dan perhitungan safety stock yang dilengkapi dengan penentuan Reorder Point yang sering dikenal dengan istilah atau Three Inventory Control Tools (3IC tools) atau 3 alat pengendalian persediaan.

Metode tersebut dinilai efektif dalam pengendalian persediaan karena terkait dengan efisiensi biaya persediaan. Perusahaan dapat menekan biaya seminimal mungkin dengan perhitungan matematis dan statistik berapa barang yang harus dipesan dan disediakan agar biayanya paling rendah. Menurut Heizer \& Render (2014) analisis ABC membagi persediaan yang dimiliki kedalam tiga golongan berdasarkan pada volume dollar tahunan. Analisis ABC adalah sebuah aplikasi persediaan dari prinsip Pareto. Prinsip Pareto menyatakan bahwa terdapat "sedikit hal yang penting dan banyak hal yang sepele." Tujuannya adalah membuat kebijakan persediaan yang memusatkan sumber daya pada komponen persediaan penting yang sedikit dan bukan pada yang banyak namun sepele.

Lebih lanjut Heizer \& Render (2014) untuk menentukan volume dollar tahunan analisis $\mathrm{ABC}$ dalam hari ini adalah volume Rupiah, permintaan tahunan dari setiap barang persediaan dihitung dan dikalikan dengan harga per unit. Barang Kelas A adalah barang barang dengan volume dollar tahunan tinggi. Walaupun barang seperti ini mungkin hanya mewakili sekitar $15 \%$ dari total persediaan barang, mereka merepresentasikan $70 \%$ hingga $80 \%$ dari total pemakaian dollar. Kelas $B$ adalah untuk barang - barang persediaan yang memiliki volume dollar tahunan menengah. Barang ini merepresentasikan $30 \%$ barang persediaan dan $15 \%$ hingga $25 \%$ dari nilai total. Barang - barng yang memiliki volume 
dollar tahunan rendah adalah Kelas $C$, yang mungkin hanya merepresentasikan 5\% dari volume dollar tahunan tetapi sekitar 55\% dari total barang persediaan.

Assauri (1999) menyebutkan kriteria selain dari volume dollar tahunan juga dapat menentukan penggolongan barang. Sebagai contoh, perubahan yang diantisipsi, permasalahan pengiriman, permasalahan kualitas, atau biaya per unit yang tinggi dapat menaikkan barang ke penggolongan yang lebih tinggi. Keuntungan dari pembagian barang persediaan ke dalam tiga kelas ini memungkinkan diterapkannya kebijakan dan kontrol untuk setiap kelas. Menurut Hadi (2004) Kebijakan yang mungkin didasarkan padaanalisis ABC meliputi hal berikut:

a) Pembelian sumber daya yang dibelanjakan pada pengembangan pemasok harus jauh lebih tinggi untuk barang A dibanding barang $\mathrm{C}$.

b) Barang A tidak seperti barang B dan C, perlu memiliki kontrol persediaan fisik yang lebih ketat ; mungkin mereka dapat diletakkan pada tempat yang lebih aman, dan mungkin akurasi catatan persediaan untuk barang A harus lebih sering diverifikasi.

c) Prediksi barang - barang A perlu dijamin keabsahannya dibandingkan dengan prediksi barang B dan $\mathrm{C}$.

Prediksi yang lebih baik, kontrol fisik, keandalan pemasok, dan pengurangan persediaan pengaman, semuanya merupakan hasil dari kebijakan manajemen persediaan yang sesuai. Analisis ABC mengarahnkan pengembangan semua kebijakan tersebut.

Menurut Rangkuti (2007) metode analisis ABC pada umumnya digunakan untuk jumlah persediaan yang banyak jumlahnya yang masing-masing barang membutuhkan analisis untuk mengetahui besarnya jumlah pemesanan. Namun demikian menurut Herjanto (2008) perlu disadari bahwa berbagai jenis barang yang ada dalam persediaan tersebut tidak seluruhnya memiliki tingkat prioritas yang sama. sehingga untuk mengetahui jenis-jenis barang yang perlu mendapat prioritas dapat dianalisis dengan metode ABC. Analisis ini dapat mengkasifikasikan seluruh jenis barang berdasarkan tingkat kepentingannya.

Menurut (Heizer \& Render, 2014) persediaan pengaman (safety stock) adalah persediaan tambahan sebagai suatu penyangga yang memungkinkan terjadinya ketidaksamaan permintaan. Adanya Safety stock bahkan security stock sebagai sumber inefisiensi (waste). Oleh karena itu sebisa mungkin persediaan minimal jumlahnya harus ditekan. Persediaan pengaman (safety stock) berguna untuk melindungi perusahaan dari risiko kehabisan bahan baku (stock out), keterlambatan penerimaan bahan baku yang dipesan, dan dapat juga bermanfaat ketika terjadi lonjakan permintaan yang tidak terprediksi sebelumnya oleh perusahaan (Hadi, 2004). Dalam analisis penyimpangan ini manajemen perusahaan menentukan seberapa jauh bahan baku yang masih dapat diterima.

Menurut Rangkuti (2007), persediaan pengaman adalah persediaan tambahan yang diadakan untuk melindungi atau menjaga kemungkinan terjadinya kekurangan bahan. Ada beberapa faktor yang menentukan besarnya persediaan pengaman, yaitu: (a) Rataan tingkat permintaan dan rataan masa tenggang; (b) Keragaman permintaan pada masa tenggang; (c) Keinginan tingkat pelayanan yang diberikan.

Perhitungan persediaan pengaman Purwanto dan Suharyadi dalam Ramadhan (2007: 136) adalah sebagai berikut:

$$
S D=\sqrt[\sqrt[2]{\frac{\sum(x-\bar{x})^{2}}{n}}]{S S=S D \times Z}
$$


Dimana: SD = Standar deviasi; $\bar{X}=$ Pemakaian sesungguhnya; $\mathrm{X}=$ Perkiraan pemakaian; $\mathrm{n}=$ Jumlah data; $\mathrm{Z}=$ nilai tabel standar deviasi untuk penyimpangan $5 \%=$ 1,65 .

Sebagai pelengkap dalam memenuhi target efektifitas dan efisiensi barang dagangan, maka metode tambahan yang dapat diterapkan adalah penentuan Reorder Point. Menurut Sugiono (2009) Reorder Point merupakan titik atau posisi (status) persediaan dimana perusahaan harus melakukan pemesanan ulang sedemikian rupa agar tidak terjadi kehabisan persediaan sehingga pada saat persediaan berada pada titik nol atau pada level safety stock, terjadi penerimaan material yang dipesan. Terutama untuk produk yang dinilai memiliki volume penjualan yang tinggi dan margin laba yang relative besar (Dewi, 2010). Terdapat beberapa hal yang harus diperhatikan dalam menentukan besarnya Reorder Point, yaitu : (1) Penggunaan / kebutuhan barang selama masa tenggang (lead time); (2) Besarnya buffer stock / safety stock.

Sehingga penentuan Reorder Ponit tampak pada rumus sebagai berikut:

$$
R O P=(\text { Lead Time } \mathrm{x} \text { Kebutuhan Perhari })+\text { Safety Stock }
$$

Salah satu perusahaan retail yang sedang berkembang adalah swalayan Mina yang berlokasi di Jalan Raya Kediri-Nganjuk, Kecamatan Grogol, Kabupaten Kediri. Berdasarkan observasi awal, terdapat beberapa permasalahan yang dihadapi Swalayan Mina terkait pengendalian persediaan barang dagangannya, yakni pada produk minyak goreng. Produk ini menjadi salah satu jenis produk yang banyak atau sering dibeli, dengan margin laba yang lumayan besar jika dibandingkan dengan produk konsumsi yang lain. Produk minyak goreng sendiri memiliki banyak varian merek dan kemasan. Permasalahan lain adalah produk minyak goreng ini memiliki lead time pemesanan yang relatif lebih lama menyebabkan sering terjadi stock out untuk merek tertentu. Swalayan Mina belum menerapkan sistem pengendalian barang dagangan yang efektif guna menjaga stabilitas keluar masuk barang dagangannya.

Berdasarkan latar belakang permasalahan diatas, maka penulis membahas hasil penelitian ini berjudul : Implementasi Kombinasi Metode ABC, Safety Stock, Dan Reorder Point Sebagai Penentu Optimasi Pengendalian Persediaan Minyak Goreng (Studi pada Swalayan Mina, Kecamatan Grogol, Kabupaten Kediri”

\section{METODE}

Penelitian ini termasuk jenis penelitian deskriptif. Tujuan dari penelitian deskriptif adalah untuk membuat deskripsi, gambaran, atau lukisan secara sistematis, faktual, dan akurat mengenai fakta-fakta, sifat-sifat serta hubungan antar fenomena yang diselidiki. Sedangkan Penelitian ini menggunakan pendekatan kuantitatif. Subyek penelitian ini adalah Swalayan Mina yang beralamat di Jalan Raya Kediri Nganjuk, Desa Wonoasri, Kecamatan Grogol, Kabupaten Kediri. Objek dari penelitian ini adalah persediaan barang dagang berupa Minyak Goreng.

Terdapat 3 (tiga) tahapan dalam Teknik analisa data menggunakan 3IC Tools, yang pertama adalah menentukan kelas dalam analisis $\mathrm{ABC}$, dan yang kedua adalah menghitung safety stock untuk produk minyak goreng yang masuk dalam kelas A.

1. Tahap analisis $\mathrm{ABC}$, dalam tahap ini terdiri dari 5 langkah perhitungan, yaitu: (a) Menghitung volume tahunan penjualan minyak goreng dengan menggandakan data 
harga dan penjualan minyak goreng tahun 2016; (b) Mengurutkan identitas minyak goreng dari volume yang paling besar; (c) Menghitung nilai kumulatif dan prosentase kumulatif; (d) Menentukan kelas

2. Tahap menghitung safety stock, perhitungan safety stock dilakukan pada produk minyak goreng yang masuk kelas A pada tahap sebelumnya. Dalam perhitungan ini terdapat 4 (empat) langkah, yaitu: (a) Menghitung standar deviasi data persediaan produk minyak goreng; (b) Menghitung safety stock

3. Tahap menentukan letak Reoder Point, dilakukan pada produk minyak goreng yang masuk kelas A pada perhitungan tahap 1 dan memiliki lead time optimum. Dalam menentukan besarnya ROP terdapat 3 langkah, yaitu: (a) Menginventarisasi data lead time minyak goreng selama 30 hari yakni dibulan Oktober 2017 untuk menentukan lead time optimum; (b) Menentukan tingkat kebutuhan barang dagangan perhari; (c) Mengalikan lead time optimum dengan kebutuhan barang dagangan perhari; (d) Menentukan ROP dengan cara menambahkan hasil kali pada langkah c dengan besaran safety stock yang telah ditentukan pada tahap ke 2 .

\section{HASIL DAN PEMBAHASAN}

\section{Analisis ABC}

Tabel 1. Identifikasi merek dan kemasan minyak goreng

\begin{tabular}{|c|c|c|c|c|c|c|c|}
\hline No. & Nama Barang & $\begin{array}{l}\text { Rata-rata } \\
\text { Per Hari }\end{array}$ & Harga & No. & Nama Barang & $\begin{array}{l}\text { Rata-rata } \\
\text { Per Hari }\end{array}$ & Harga \\
\hline 1 & IKAN DORANG MAS 2L BTL & 7 & 30.900 & 44 & FRAIS WELL 2L REF & 2 & 20.500 \\
\hline 2 & HEMART 5L JRG & 49 & 60.500 & 45 & FORTUNE 2L BOT & 72 & 24.200 \\
\hline 3 & BIMOLI SP 5LT JRG & 71 & 65.700 & 46 & GURIH 1L REF & 5 & 11.200 \\
\hline 4 & SUNCO 5L GALON & 11 & 70.500 & 47 & SANIA 5L JRG & 21 & 64.200 \\
\hline 5 & MMS SOY BEAN OIL 900M & 8 & 41.700 & 48 & IKAN DORANG SP 1L BTL & 11 & 23.300 \\
\hline 6 & DAMAI SP 5L JRG & 9 & 64.800 & 49 & SUNCO 1L REF & 64 & 13.200 \\
\hline 7 & BIMOLI 5LT JRG & 51 & 64.300 & 50 & KUNCI MAS 1L REF & 16 & 12.000 \\
\hline 8 & ROSE BRAND 2L REF & 44 & 23.300 & 51 & SUNCO 1L BTL & 14 & 14.700 \\
\hline 9 & ROSE BRAND 5L JRG & 21 & 50.250 & 52 & MASKU 2L REF & 5 & 21.800 \\
\hline 10 & BIMOLI SP 2LT REF & 66 & 25.700 & 53 & FORTUNE 1L REF & 9 & 11.000 \\
\hline 11 & CCO 1L BOT & 21 & 26.800 & 54 & TAWON 1L REF & 26 & 12.700 \\
\hline 12 & SOVIA 5L JRG & 20 & 60.600 & 55 & BIMOLI 250 REF & 23 & 4.300 \\
\hline 13 & SOVIA 2L BOT & 22 & 24.900 & 56 & BIMOLI SP 250M & 37 & 5.150 \\
\hline 14 & BIMOLI 1LT REF & 57 & 12.700 & 57 & TS CORN OIL 1L REF & 9 & 64.400 \\
\hline 15 & SARI MURNI 2L REF & 14 & 22.200 & 58 & TS CORN OIL 946M BOT & 11 & 64.400 \\
\hline 16 & BIMOLI 2L BOT & 61 & 28.200 & 59 & FILMA 1L REF & 68 & 11.700 \\
\hline 17 & HEMART 2L REF & 7 & 22.600 & 60 & AVENA 2L REF & 12 & 25.000 \\
\hline 18 & SEDAAP 2L REF & 82 & 22.600 & 61 & HEMART 500M REF & 6 & 5.900 \\
\hline 19 & BIMOLI SP 2L BTL & 64 & 29.650 & 62 & SOVIA 1L REF & 15 & 11.000 \\
\hline 20 & IKAN DORANG MAS 5L BTL & 7 & 68.400 & 63 & DAMAI SP 1L REF & 17 & 10.900 \\
\hline 21 & FILMA 2L REF & 20 & 23.600 & 64 & KUNCI MAS 225ML & 90 & 6.600 \\
\hline 22 & SUNCO 2L BTL & 22 & 28.500 & 65 & MADINA 5L JRG & 32 & 56.500 \\
\hline 23 & BIMOLI SP 1LT REF & 103 & 13.500 & 66 & IKAN DORANG SP 5L BTL & 12 & 111.000 \\
\hline 24 & SANIA 2L REF & 54 & 22.000 & 67 & SIIP $4,8 \mathrm{~L}$ & 12 & 53.700 \\
\hline 25 & $\mathrm{CCO} 2 \mathrm{~L} \mathrm{BOT}$ & 5 & 52.900 & 68 & IKAN DORANG MAS 5L BTL & 11 & 26.700 \\
\hline 26 & KUNCI MAS 2L REF & 80 & 24.600 & 69 & DAMAI SP 2L REF & 23 & 21.200 \\
\hline 27 & FILMA 5L JRG & 23 & 70.000 & 70 & BIMOLI 1L BOT & 11 & 14.600 \\
\hline 28 & FORTUNE 2L REF & 47 & 21.800 & 71 & HEMART 1L REF & 63 & 11.300 \\
\hline 29 & SANIA 2L BOT & 16 & 24.900 & 72 & IKAN DORANG SP 2L BTL & 21 & 45.800 \\
\hline 30 & INGA CO 2L BOT & 24 & 48.800 & 73 & IKAN DORANG MAS 1L BTL & 10 & 14.750 \\
\hline 31 & MASKU 1L REF & 12 & 11.400 & 74 & IKAN DORANG SP 1,9L REF & 12 & 41.200 \\
\hline 32 & MMS CORN OIL 900M & 11 & 45.400 & 75 & FITRI 900 REF & 5 & 10.000 \\
\hline 33 & IKAN DORANG MAS 950M & 17 & 14.200 & 76 & FITRI $1800 \mathrm{REF}$ & 3 & 19.500 \\
\hline 34 & BIMOLI 2LT REF & 32 & 24.000 & 77 & FRAIS WELL 1L REF & 18 & 10.100 \\
\hline 35 & FORTUNE 5L JRG & 11 & 60.100 & 78 & MADINA 1L REF & 8 & 11.500 \\
\hline 36 & SEDAAP 1L REF & 19 & 12.900 & 79 & ROSE BRAND 1L REF & 124 & 11.750 \\
\hline 37 & FORTUNE 1L BOT & 93 & 12.400 & 80 & IKAN DORANG SP 950M REF & 4 & 20.900 \\
\hline 38 & SUNCO 2L REF & 33 & 25.600 & 81 & SOVIA 1L BOT & 4 & 13.300 \\
\hline
\end{tabular}


Purnomo dan Riani: Implementasi Kombinasi 3IC Tools Sebagai Penentu Optimasi...

\begin{tabular}{|c|c|c|c|c|c|c|c|}
\hline 39 & SARI MURNI 1L REF & 15 & 11.300 & 82 & BIMOLI SP 1L BOT & 81 & 15.200 \\
\hline 40 & SOVIA 2L REF & 40 & 22.100 & 83 & DUNIA 900M & 12 & 9.950 \\
\hline 41 & SANIA 1L REF & 91 & 11.300 & 84 & ROSE BRAND 240M CUP & 134 & 2.700 \\
\hline 42 & MADINA 2L REF & 14 & 22.300 & 85 & AVENA 1L REF & 13 & 12.800 \\
\hline 43 & SANIA 1L BTL & 50 & 13.300 & 86 & IKAN HIU 450 BOT & 5 & 5.250 \\
\hline
\end{tabular}

Sumber: data sekunder perusahaan, diolah, 2017

Berdasarkan data diatas, dapat diidentifikasi sebanyak 86 kemasan minyak goreng dari berbagai merk. Adapun permintaan perhari paling banyak adalah pada minyak goreng merek Rose Brand pada kemasan 240m Cup, sedangkan harga paling mahal adalah Merek Ikan Dorang SP 5L Kemasan Botol.

\section{Mengurutkan identitas minyak goreng dari volume permintaan tahunan yang paling besar}

Tabel 2. Urutan identitas minyak goreng berdasarkan volume tahunan

\begin{tabular}{|c|c|c|c|c|c|}
\hline No. & Nama Barang & Vol. Tahunan & No. & Nama Barang & Vol. Tahunan \\
\hline 1 & BIMOLI SP 5LT JRG & Rp1.679.292.000 & 44 & MMS CORN OIL 900M & Rp179.784.000 \\
\hline 2 & BIMOLI 5LT JRG & Rp1.180.548.000 & 45 & IKAN DORANG SP 1,9L REF & Rp177.984.000 \\
\hline 3 & HEMART 5L JRG & Rp1.067.220.000 & 46 & DAMAI SP 2L REF & Rp175.536.000 \\
\hline 4 & KUNCI MAS 2L REF & Rp708.480.000 & 47 & IKAN DORANG MAS 5L BTL & Rp172.368.000 \\
\hline 5 & BIMOLI SP 2L BTL & Rp683.136.000 & 48 & FILMA 2L REF & Rp169.920.000 \\
\hline 6 & SEDAAP 2L REF & Rp667.152.000 & 49 & SANIA 2L BOT & Rp143.424.000 \\
\hline 7 & MADINA 5L JRG & Rp650.880.000 & 50 & ROSE BRAND 240M CUP & Rp130.248.000 \\
\hline 8 & FORTUNE 2L BOT & Rp627.264.000 & 51 & MMS SOY BEAN OIL 900M & Rp120.096.000 \\
\hline 9 & BIMOLI 2L BOT & Rp619.272.000 & 52 & TAWON 1L REF & Rp118.872.000 \\
\hline 10 & BIMOLI SP 2LT REF & Rp610.632.000 & 53 & MADINA 2L REF & Rp112.392.000 \\
\hline 11 & FILMA 5L JRG & Rp579.600.000 & 54 & SARI MURNI 2L REF & Rp111.888.000 \\
\hline 12 & ROSE BRAND 1L REF & Rp524.520.000 & 55 & AVENA 2L REF & Rp108.000.000 \\
\hline 13 & BIMOLI SP 1LT REF & Rp500.580.000 & 56 & IKAN DORANG MAS 5L BTL & Rp105.732.000 \\
\hline 14 & SANIA 5L JRG & Rp485.352.000 & 57 & $\mathrm{CCO} 2 \mathrm{~L}$ BOT & Rp95.220.000 \\
\hline 15 & IKAN DORANG SP 5L BTL & Rp479.520.000 & 58 & IKAN DORANG SP 1L BTL & Rp92.268.000 \\
\hline 16 & BIMOLI SP 1L BOT & Rp443.232.000 & 59 & SEDAAP 1L REF & Rp88.236.000 \\
\hline 17 & SOVIA 5L JRG & Rp436.320.000 & 60 & IKAN DORANG MAS 950M & Rp86.904.000 \\
\hline 18 & SANIA 2L REF & Rp427.680.000 & 61 & IKAN DORANG MAS 2L BTL & Rp77.868.000 \\
\hline 19 & INGA CO 2L BOT & Rp421.632.000 & 62 & SUNCO 1L BTL & Rp74.088.000 \\
\hline 20 & FORTUNE 1L BOT & Rp415.152.000 & 63 & KUNCI MAS 1L REF & Rp69.120.000 \\
\hline 21 & ROSE BRAND 5L JRG & Rp379.890.000 & 64 & BIMOLI SP 250M & Rp68.598.000 \\
\hline 22 & SANIA 1L REF & Rp370.188.000 & 65 & DAMAI SP 1L REF & Rp66.708.000 \\
\hline 23 & ROSE BRAND 2L REF & Rp369.072.000 & 66 & FRAIS WELL 1L REF & Rp65.448.000 \\
\hline 24 & FORTUNE 2L REF & Rp368.856.000 & 67 & SARI MURNI 1L REF & Rp61.020.000 \\
\hline 25 & IKAN DORANG SP 2L BTL & Rp346.248.000 & 68 & AVENA 1L REF & Rp59.904.000 \\
\hline 26 & SOVIA 2L REF & Rp318.240.000 & 69 & SOVIA 1L REF & Rp59.400.000 \\
\hline 27 & SUNCO 2L REF & Rp304.128.000 & 70 & BIMOLI 1L BOT & Rp57.816.000 \\
\hline 28 & SUNCO 1L REF & Rp304.128.000 & 71 & HEMART 2L REF & Rp56.952.000 \\
\hline 29 & FILMA 1L REF & Rp286.416.000 & 72 & IKAN DORANG MAS 1L BTL & Rp53.100.000 \\
\hline 30 & SUNCO 5L GALON & Rp279.180.000 & 73 & MASKU 1L REF & Rp49.248.000 \\
\hline 31 & BIMOLI 2LT REF & Rp276.480.000 & 74 & DUNIA 900M & Rp42.984.000 \\
\hline 32 & BIMOLI 1LT REF & Rp260.604.000 & 75 & MASKU 2L REF & Rp39.240.000 \\
\hline 33 & HEMART 1L REF & Rp256.284.000 & 76 & FORTUNE 1L REF & Rp35.640.000 \\
\hline 34 & TS CORN OIL 946M BOT & Rp255.024.000 & 77 & BIMOLI 250 REF & Rp35.604.000 \\
\hline 35 & SANIA 1L BTL & Rp239.400.000 & 78 & MADINA 1L REF & Rp33.120.000 \\
\hline 36 & FORTUNE 5L JRG & Rp237.996.000 & 79 & IKAN DORANG SP 950M REF & Rp30.096.000 \\
\hline 37 & SIIP $4,8 \mathrm{~L}$ & Rp231.984.000 & 80 & FITRI 1800 REF & Rp21.060.000 \\
\hline 38 & SUNCO 2L BTL & Rp225.720.000 & 81 & GURIH 1L REF & Rp20.160.000 \\
\hline 39 & KUNCI MAS 225ML & Rp213.840.000 & 82 & SOVIA $1 \mathrm{~L}$ BOT & Rp19.152.000 \\
\hline 40 & DAMAI SP 5L JRG & Rp209.952.000 & 83 & FITRI 900 REF & Rp18.000.000 \\
\hline 41 & TS CORN OIL 1L REF & Rp208.656.000 & 84 & FRAIS WELL 2L REF & Rp14.760.000 \\
\hline 42 & CCO 1L BOT & Rp202.608.000 & 85 & HEMART 500M REF & Rp12.744.000 \\
\hline 43 & SOVIA 2L BOT & Rp197.208.000 & 86 & IKAN HIU 450 BOT & Rp9.450.000 \\
\hline
\end{tabular}

Sumber: Data sekunder perusahaan, diolah, 2017

Tabel 2 diatas menunjukkan urutan volume tahunan minyak goreng, volume tahunan merupakan hasil kali dari permintaan perbulan dengan harga perunit nya. Nilai volume 
tahunan paling besar diperoleh minyak goreng merek Bimoli SP 5LT Jrg, sedangkan nilai volume tahunan terendah ditunjukkan pada merek Ikan Hiu 450 Bot.

\section{Menghitung nilai kumulatif dan prosentase kumulatif}

Tabel 3. Nilai Kumulatif dan Prosentase Kumulatif

\begin{tabular}{|c|c|c|c|c|c|c|c|}
\hline No. & Nama Barang & Kumulatif & $\begin{array}{c}\% \\
\text { Kum }\end{array}$ & No. & Nama Barang & Kumulatif & $\begin{array}{c}\% \\
\text { Kum }\end{array}$ \\
\hline 1 & BIMOLI SP 5LT JRG & Rp1.679.292.000 & 7,34 & 44 & MMS CORN OIL 900M & Rp19.729.350.000 & 86,19 \\
\hline 2 & BIMOLI 5LT JRG & $\mathrm{Rp} 2.859 .840 .000$ & 12,49 & 45 & IKAN DORANG SP 1,9L REF & Rp19.907.334.000 & 86,97 \\
\hline 3 & HEMART 5L JRG & Rp3.927.060.000 & 17,16 & 46 & DAMAI SP 2L REF & Rp20.082.870.000 & 87,74 \\
\hline 4 & KUNCI MAS 2L REF & Rp4.635.540.000 & 20,25 & 47 & IKAN DORANG MAS 5L BTL & Rp20.255.238.000 & 88,49 \\
\hline 5 & BIMOLI SP 2L BTL & Rp5.318.676.000 & 23,24 & 48 & FILMA 2L REF & Rp20.425.158.000 & 89,23 \\
\hline 6 & SEDAAP 2L REF & Rp5.985.828.000 & 26,15 & 49 & SANIA 2L BOT & Rp20.568.582.000 & 89,86 \\
\hline 7 & MADINA 5L JRG & Rp6.636.708.000 & 28,99 & 50 & ROSE BRAND 240M CUP & Rp20.698.830.000 & 90,43 \\
\hline 8 & FORTUNE 2L BOT & Rp7.263.972.000 & 31,73 & 51 & MMS SOY BEAN OIL 900M & Rp20.818.926.000 & 90,95 \\
\hline 9 & BIMOLI 2L BOT & Rp7.883.244.000 & 34,44 & 52 & TAWON 1L REF & Rp20.937.798.000 & 91,47 \\
\hline 10 & BIMOLI SP 2LT REF & Rp8.493.876.000 & 37,11 & 53 & MADINA 2L REF & Rp21.050.190.000 & 91,96 \\
\hline 11 & FILMA 5L JRG & Rp9.073.476.000 & 39,64 & 54 & SARI MURNI 2L REF & $\mathrm{Rp} 21.162 .078 .000$ & 92,45 \\
\hline 12 & ROSE BRAND 1L REF & Rp9.597.996.000 & 41,93 & 55 & AVENA 2L REF & $\mathrm{Rp} 21.270 .078 .000$ & 92,92 \\
\hline 13 & BIMOLI SP 1LT REF & Rp10.098.576.000 & 44,12 & 56 & IKAN DORANG MAS 5L BTL & Rp21.375.810.000 & 93,39 \\
\hline 14 & SANIA 5L JRG & Rp10.583.928.000 & 46,24 & 57 & $\mathrm{CCO} 2 \mathrm{~L} \mathrm{BOT}$ & $\mathrm{Rp} 21.471 .030 .000$ & 93,80 \\
\hline 15 & IKAN DORANG SP 5L BTL & Rp11.063.448.000 & 48,33 & 58 & IKAN DORANG SP 1L BTL & Rp21.563.298.000 & 94,21 \\
\hline 16 & BIMOLI SP 1L BOT & Rp11.506.680.000 & 50,27 & 59 & SEDAAP 1L REF & Rp21.651.534.000 & 94,59 \\
\hline 17 & SOVIA 5L JRG & Rp11.943.000.000 & 52,18 & 60 & IKAN DORANG MAS 950M & $\mathrm{Rp} 21.738 .438 .000$ & 94,97 \\
\hline 18 & SANIA 2L REF & Rp12.370.680.000 & 54,04 & 61 & IKAN DORANG MAS 2L BTL & Rp21.816.306.000 & 95,31 \\
\hline 19 & INGA CO 2L BOT & Rp12.792.312.000 & 55,89 & 62 & SUNCO 1L BTL & Rp21.890.394.000 & 95,63 \\
\hline 20 & FORTUNE 1L BOT & Rp13.207.464.000 & 57,70 & 63 & KUNCI MAS 1L REF & Rp21.959.514.000 & 95,94 \\
\hline 21 & ROSE BRAND 5L JRG & Rp13.587.354.000 & 59,36 & 64 & BIMOLI SP 250M & Rp22.028.112.000 & 96,24 \\
\hline 22 & SANIA 1L REF & Rp13.957.542.000 & 60,98 & 65 & DAMAI SP 1L REF & Rp22.094.820.000 & 96,53 \\
\hline 23 & ROSE BRAND 2L REF & Rp14.326.614.000 & 62,59 & 66 & FRAIS WELL 1L REF & Rp22.160.268.000 & 96,81 \\
\hline 24 & FORTUNE 2L REF & Rp14.695.470.000 & 64,20 & 67 & SARI MURNI 1L REF & Rp22.221.288.000 & 97,08 \\
\hline 25 & IKAN DORANG SP 2L BTL & Rp15.041.718.000 & 65,71 & 68 & AVENA 1L REF & Rp22.281.192.000 & 97,34 \\
\hline 26 & SOVIA 2L REF & Rp15.359.958.000 & 67,10 & 69 & SOVIA 1L REF & Rp22.340.592.000 & 97,60 \\
\hline 27 & SUNCO 2L REF & Rp15.664.086.000 & 68,43 & 70 & BIMOLI 1L BOT & Rp22.398.408.000 & 97,85 \\
\hline 28 & SUNCO 1L REF & Rp15.968.214.000 & 69,76 & 71 & HEMART 2L REF & Rp22.455.360.000 & 98,10 \\
\hline 29 & FILMA 1L REF & Rp16.254.630.000 & 71,01 & 72 & IKAN DORANG MAS 1L BTL & $\mathrm{Rp} 22.508 .460 .000$ & 98,33 \\
\hline 30 & SUNCO 5L GALON & Rp16.533.810.000 & 72,23 & 73 & MASKU 1L REF & Rp22.557.708.000 & 98,55 \\
\hline 31 & BIMOLI 2LT REF & Rp16.810.290.000 & 73,44 & 74 & DUNIA 900M & $\mathrm{Rp} 22.600 .692 .000$ & 98,74 \\
\hline 32 & BIMOLI 1LT REF & Rp17.070.894.000 & 74,58 & 75 & MASKU 2L REF & Rp22.639.932.000 & 98,91 \\
\hline 33 & HEMART 1L REF & Rp17.327.178.000 & 75,70 & 76 & FORTUNE 1L REF & Rp22.675.572.000 & 99,06 \\
\hline 34 & TS CORN OIL 946M BOT & Rp17.582.202.000 & 76,81 & 77 & BIMOLI 250 REF & $\mathrm{Rp} 22.711 .176 .000$ & 99,22 \\
\hline 35 & SANIA 1L BTL & Rp17.821.602.000 & 77,86 & 78 & MADINA 1L REF & Rp22.744.296.000 & 99,36 \\
\hline 36 & FORTUNE 5L JRG & Rp18.059.598.000 & 78,90 & 79 & IKAN DORANG SP 950M REF & Rp22.774.392.000 & 99,50 \\
\hline 37 & SIIP $4,8 \mathrm{~L}$ & Rp18.291.582.000 & 79,91 & 80 & FITRI 1800 REF & $\mathrm{Rp} 22.795 .452 .000$ & 99,59 \\
\hline 38 & SUNCO 2L BTL & Rp18.517.302.000 & 80,90 & 81 & GURIH 1L REF & $\mathrm{Rp} 22.815 .612 .000$ & 99,68 \\
\hline 39 & KUNCI MAS 225ML & Rp18.731.142.000 & 81,83 & 82 & SOVIA 1L BOT & $\mathrm{Rp} 22.834 .764 .000$ & 99,76 \\
\hline 40 & DAMAI SP 5L JRG & Rp18.941.094.000 & 82,75 & 83 & FITRI 900 REF & $\mathrm{Rp} 22.852 .764 .000$ & 99,84 \\
\hline 41 & TS CORN OIL 1L REF & Rp19.149.750.000 & 83,66 & 84 & FRAIS WELL 2L REF & $\mathrm{Rp} 22.867 .524 .000$ & 99,90 \\
\hline 42 & CCO 1L BOT & Rp19.352.358.000 & 84,55 & 85 & HEMART 500M REF & Rp22.880.268.000 & 99,96 \\
\hline 43 & SOVIA 2L BOT & Rp19.549.566.000 & 85,41 & 86 & IKAN HIU 450 BOT & Rp22.889.718.000 & 100,00 \\
\hline
\end{tabular}

Sumber: Data sekunder perusahaan, diolah, 2017

Nilai Kumulatif diperoleh berdasarkan tabel sebelumnya, yakni pada volume tahunan ditambahkan volume tahunan urutan berikutnya, sehingga menghasilkan volume tahunan 
total sebesar Rp. 22.889.718.000,00. Nilai volume tahunan total digunakan untuk menghitung prosentae kumulatif.

\section{Menentukan kelas}

Tabel 4. Penentuan kelas

\begin{tabular}{|c|c|c|c|c|c|c|c|}
\hline No. & Nama Barang & $\%$ Kum & Kelas & No. & Nama Barang & $\begin{array}{c}\% \\
\text { Kum }\end{array}$ & Kelas \\
\hline 1 & BIMOLI SP 5LT JRG & 7,34 & A & 44 & MMS CORN OIL 900M & 86,19 & B \\
\hline 2 & BIMOLI 5LT JRG & 12,49 & A & 45 & IKAN DORANG SP 1,9L REF & 86,97 & B \\
\hline 3 & HEMART 5L JRG & 17,16 & A & 46 & DAMAI SP 2L REF & 87,74 & B \\
\hline 4 & KUNCI MAS 2L REF & 20,25 & A & 47 & IKAN DORANG MAS 5L BTL & 88,49 & B \\
\hline 5 & BIMOLI SP 2L BTL & 23,24 & A & 48 & FILMA 2L REF & 89,23 & B \\
\hline 6 & SEDAAP 2L REF & 26,15 & A & 49 & SANIA 2L BOT & 89,86 & B \\
\hline 7 & MADINA 5L JRG & 28,99 & A & 50 & ROSE BRAND 240M CUP & 90,43 & $\mathrm{C}$ \\
\hline 8 & FORTUNE 2L BOT & 31,73 & A & 51 & MMS SOY BEAN OIL 900M & 90,95 & $\mathrm{C}$ \\
\hline 9 & BIMOLI 2L BOT & 34,44 & A & 52 & TAWON 1L REF & 91,47 & $\mathrm{C}$ \\
\hline 10 & BIMOLI SP 2LT REF & 37,11 & A & 53 & MADINA 2L REF & 91,96 & $\mathrm{C}$ \\
\hline 11 & FILMA 5L JRG & 39,64 & A & 54 & SARI MURNI 2L REF & 92,45 & $\mathrm{C}$ \\
\hline 12 & ROSE BRAND 1L REF & 41,93 & A & 55 & AVENA 2L REF & 92,92 & $\mathrm{C}$ \\
\hline 13 & BIMOLI SP 1LT REF & 44,12 & A & 56 & IKAN DORANG MAS 5L BTL & 93,39 & $\mathrm{C}$ \\
\hline 14 & SANIA 5L JRG & 46,24 & A & 57 & $\mathrm{CCO} 2 \mathrm{~L} \mathrm{BOT}$ & 93,80 & $\mathrm{C}$ \\
\hline 15 & IKAN DORANG SP 5L BTL & 48,33 & A & 58 & IKAN DORANG SP 1L BTL & 94,21 & $\mathrm{C}$ \\
\hline 16 & BIMOLI SP 1L BOT & 50,27 & A & 59 & SEDAAP 1L REF & 94,59 & $\mathrm{C}$ \\
\hline 17 & SOVIA 5L JRG & 52,18 & A & 60 & IKAN DORANG MAS 950M & 94,97 & $\mathrm{C}$ \\
\hline 18 & SANIA 2L REF & 54,04 & A & 61 & IKAN DORANG MAS 2L BTL & 95,31 & $\mathrm{C}$ \\
\hline 19 & INGA CO 2L BOT & 55,89 & A & 62 & SUNCO 1L BTL & 95,63 & $\mathrm{C}$ \\
\hline 20 & FORTUNE 1L BOT & 57,70 & A & 63 & KUNCI MAS 1L REF & 95,94 & $\mathrm{C}$ \\
\hline 21 & ROSE BRAND 5L JRG & 59,36 & A & 64 & BIMOLI SP 250M & 96,24 & $\mathrm{C}$ \\
\hline 22 & SANIA 1L REF & 60,98 & A & 65 & DAMAI SP 1L REF & 96,53 & $\mathrm{C}$ \\
\hline 23 & ROSE BRAND 2L REF & 62,59 & A & 66 & FRAIS WELL 1L REF & 96,81 & $\mathrm{C}$ \\
\hline 24 & FORTUNE 2L REF & 64,20 & A & 67 & SARI MURNI 1L REF & 97,08 & $\mathrm{C}$ \\
\hline 25 & IKAN DORANG SP 2L BTL & 65,71 & A & 68 & AVENA 1L REF & 97,34 & $\mathrm{C}$ \\
\hline 26 & SOVIA 2L REF & 67,10 & A & 69 & SOVIA 1L REF & 97,60 & $\mathrm{C}$ \\
\hline 27 & SUNCO 2L REF & 68,43 & A & 70 & BIMOLI 1L BOT & 97,85 & $\mathrm{C}$ \\
\hline 28 & SUNCO 1L REF & 69,76 & A & 71 & HEMART 2L REF & 98,10 & $\mathrm{C}$ \\
\hline 29 & FILMA 1L REF & 71,01 & B & 72 & IKAN DORANG MAS 1L BTL & 98,33 & $\mathrm{C}$ \\
\hline 30 & SUNCO 5L GALON & 72,23 & B & 73 & MASKU 1L REF & 98,55 & $\mathrm{C}$ \\
\hline 31 & BIMOLI 2LT REF & 73,44 & B & 74 & DUNIA $900 \mathrm{M}$ & 98,74 & $\mathrm{C}$ \\
\hline 32 & BIMOLI 1LT REF & 74,58 & B & 75 & MASKU 2L REF & 98,91 & $\mathrm{C}$ \\
\hline 33 & HEMART 1L REF & 75,70 & B & 76 & FORTUNE 1L REF & 99,06 & $\mathrm{C}$ \\
\hline 34 & TS CORN OIL 946M BOT & 76,81 & B & 77 & BIMOLI 250 REF & 99,22 & $\mathrm{C}$ \\
\hline 35 & SANIA 1L BTL & 77,86 & B & 78 & MADINA 1L REF & 99,36 & $\mathrm{C}$ \\
\hline 36 & FORTUNE 5L JRG & 78,90 & B & 79 & IKAN DORANG SP 950M REF & 99,50 & $\mathrm{C}$ \\
\hline 37 & SIIP 4,8L & 79,91 & B & 80 & FITRI 1800 REF & 99,59 & $\mathrm{C}$ \\
\hline 38 & SUNCO 2L BTL & 80,90 & B & 81 & GURIH 1L REF & 99,68 & $\mathrm{C}$ \\
\hline 39 & KUNCI MAS 225ML & 81,83 & B & 82 & SOVIA 1L BOT & 99,76 & $\mathrm{C}$ \\
\hline 40 & DAMAI SP 5L JRG & 82,75 & B & 83 & FITRI 900 REF & 99,84 & $\mathrm{C}$ \\
\hline 41 & TS CORN OIL 1L REF & 83,66 & B & 84 & FRAIS WELL 2L REF & 99,90 & $\mathrm{C}$ \\
\hline 42 & CCO 1L BOT & 84,55 & B & 85 & HEMART 500M REF & 99,96 & $\mathrm{C}$ \\
\hline 43 & SOVIA 2L BOT & 85,41 & $\mathrm{~B}$ & 86 & IKAN HIU 450 BOT & 100,00 & $\mathrm{C}$ \\
\hline
\end{tabular}

Sumber: Data sekunder perusahaan, diolah, 2017

Tabel 4 diatas menunjukkan bahwa terdapat 28 item minyak goreng yang masuk pada kelas A, 21 item masuk pada kelas B, sedangkan sisanya sebanyak 31 item masuk pada kelas C. Penentuan kelas ini dapat digunakan sebagai acuan dalam pengambilan keputusan mengenai item minyak goreng apa saja yang harus di utamakan persediaanya, karena terkait dengan antisipasi out of stock.

\section{Perhitungan Safety Stock}

a. Menghitung standar deviasi data persediaan produk minyak goreng 
Tabel 5. Perhitungan standar deviasi

\begin{tabular}{llllll}
\hline No. & Nama Barang & STDEV & No. & Nama Barang & STDEV \\
\hline 1 & BIMOLI SP 5LT JRG & 17,88 & 15 & IKAN DORANG SP 5L BTL & 12,96 \\
2 & BIMOLI 5LT JRG & 12,92 & 16 & BIMOLI SP 1L BOT & 14,40 \\
3 & HEMART 5L JRG & 29,28 & 17 & SOVIA 5L JRG & 17,62 \\
4 & KUNCI MAS 2L REF & 21,90 & 18 & SANIA 2L REF & 14,57 \\
5 & BIMOLI SP 2L BTL & 28,52 & 19 & INGA CO 2L BOT & 12,43 \\
6 & SEDAAP 2L REF & 251,77 & 20 & FORTUNE 1L BOT & 41,51 \\
7 & MADINA 5L JRG & 31,64 & 21 & ROSE BRAND 5L JRG & 8,06 \\
8 & FORTUNE 2L BOT & 28,07 & 22 & SANIA 1L REF & 46,30 \\
9 & BIMOLI 2L BOT & 23,23 & 23 & ROSE BRAND 2L REF & 71,23 \\
10 & BIMOLI SP 2LT REF & 28,88 & 24 & FORTUNE 2L REF & 24,03 \\
11 & FILMA 5L JRG & 22,48 & 25 & IKAN DORANG SP 2L BTL & 18,54 \\
12 & ROSE BRAND 1L REF & 115,38 & 26 & SOVIA 2L REF & 26,35 \\
13 & BIMOLI SP 1LT REF & 162,01 & 27 & SUNCO 2L REF & 28,42 \\
14 & SANIA 5L JRG & 27,81 & 28 & SUNCO 1L REF & 27,58 \\
\hline
\end{tabular}

Sumber: Data sekunder perusahaan, diolah, 2017

Standar deviasi dalam hal ini merupakan angka penyimpangan standar berdasarkan data permintaan perbulan, adapun penyimpangan terbesar dihasilkan oleh item merek Sedaap 2L Ref, sedangkan penyimpangan terkecil ditunjukkan oleh item Rose Brand 5L Jrg, yakni 8. Hasil perhitungan standar deviasi ini digunakan untuk menentukan level safety stock.

\section{Menghitung safety stock}

Tabel 6. Penentuan besarnya Safety Stock

\begin{tabular}{clccclcc}
\hline No. & \multicolumn{1}{c}{ Nama Barang } & STDEV & SS & No. & \multicolumn{1}{c}{ Nama Barang } & STDEV & SS \\
\hline 1 & BIMOLI SP 5LT JRG & 17,88 & 30 & 15 & IKAN DORANG SP 5L BTL & 12,96 & 21 \\
2 & BIMOLI 5LT JRG & 12,92 & 21 & 16 & BIMOLI SP 1L BOT & 14,40 & 24 \\
3 & HEMART 5L JRG & 29,28 & 48 & 17 & SOVIA 5L JRG & 17,62 & 29 \\
4 & KUNCI MAS 2L REF & 21,90 & 36 & 18 & SANIA 2L REF & 14,57 & 24 \\
5 & BIMOLI SP 2L BTL & 28,52 & 47 & 19 & INGA CO 2L BOT & 12,43 & 21 \\
6 & SEDAAP 2L REF & 251,77 & 415 & 20 & FORTUNE 1L BOT & 41,51 & 68 \\
7 & MADINA 5L JRG & 31,64 & 52 & 21 & ROSE BRAND 5L JRG & 8,06 & 13 \\
8 & FORTUNE 2L BOT & 28,07 & 46 & 22 & SANIA 1L REF & 46,30 & 76 \\
9 & BIMOLI 2L BOT & 23,23 & 38 & 23 & ROSE BRAND 2L REF & 71,23 & 118 \\
10 & BIMOLI SP 2LT REF & 28,88 & 48 & 24 & FORTUNE 2L REF & 24,03 & 40 \\
11 & FILMA 5L JRG & 22,48 & 37 & 25 & IKAN DORANG SP 2L BTL & 18,54 & 31 \\
12 & ROSE BRAND 1L REF & 115,38 & 190 & 26 & SOVIA 2L REF & 26,35 & 43 \\
13 & BIMOLI SP 1LT REF & 162,01 & 267 & 27 & SUNCO 2L REF & 28,42 & 47 \\
14 & SANIA 5L JRG & 27,81 & 46 & 28 & SUNCO 1L REF & 27,58 & 45 \\
\hline
\end{tabular}

Sumber: Data sekunder perusahaan, diolah, 2017

Persediaan yang harus ada digudang adalah paling banyak dari item Sedaap 2L Ref yaitu 252 buah. Sedangkan safety stock paling sedikit pada item Bimoli 5L, Ikan Dorang SP 5L BTL, dan Inga Co 2L BOT masing-masing sebanyak 21 buah.

\section{Menentukan Reorder Point}

a. Menginventarisasi data lead time minyak goreng selama 30 hari yakni dibulan Oktober 2017 untuk menentukan lead time optimum 
Data lead time perusahaan untuk produk minyak goreng diketahui bervariasi antara 4, 5, 6, dan 7 hari pengiriman sampai barang datang di gudang Swalayan Mina, sehingga dalam penelitian ini akan dihitung reorder point untuk lead time dengan frekuensi terbanyak yang menunjukkan lead time tersebut paling sering terjadi. Berikut adalah data lead time selama 30 kali pemesanan:

Tabel 7. Data lead time selama 30 kali pemesanan

\begin{tabular}{cc}
\hline Lead time (hari) & Frekuensi \\
\hline 4 & 3 \\
5 & 8 \\
6 & 5 \\
7 & 14 \\
Jumlah pemesanan & $30 \mathrm{kali}$ \\
\hline Sumber: data perusahaan, diolah peneliti 2017.
\end{tabular}

Dari Tabel 7 tampak bahwa lead time yang paling sering terjadi adalah 7 hari dengan frekuensi 14 kali pemesanan. Sehingga lead time ini digunakan dalam perhitungan menentukan besarnya Reorder Point.

b. Menentukan tingkat kebutuhan barang dagangan perhari. Langkah kedua dalam tahap menentukan reorder point adalah menghitung tingkat kebutuhan perhari, dengan ketentuan perusahaan bahwa hari kerja ditentukan selama 364 hari dalam setahun. Table berikut merupakan data kebutuhan produk minyak goreng pertahun untuk minyak goreng yang masuk dalam kelas A dalam analisis ABC.

Tabel 8. Data kebutuhan minyak goreng perhari

\begin{tabular}{|c|c|c|c|c|c|c|c|}
\hline No. & Nama Barang & $\begin{array}{l}\text { Kebutuhan } \\
\text { pertahun }\end{array}$ & $\begin{array}{l}\text { Kebutuhan } \\
\text { Perhari }\end{array}$ & No. & Nama Barang & $\begin{array}{l}\text { Kebutuhan } \\
\text { Pertahun }\end{array}$ & $\begin{array}{l}\text { Kebutuhan } \\
\text { Perhari }\end{array}$ \\
\hline 1 & BIMOLI SP 5LT JRG & 25560 & 71 & 15 & $\begin{array}{l}\text { IKAN DORANG } \\
\text { SP 5L BTL }\end{array}$ & 4320 & 12 \\
\hline 2 & BIMOLI 5LT JRG & 18360 & 51 & 16 & $\begin{array}{l}\text { BIMOLI SP 1L } \\
\text { BOT }\end{array}$ & 29160 & 81 \\
\hline 3 & HEMART 5L JRG & 17640 & 49 & 17 & SOVIA 5L JRG & 7200 & 20 \\
\hline 4 & KUNCI MAS 2L REF & 28800 & 80 & 18 & SANIA 2L REF & 19440 & 54 \\
\hline 5 & BIMOLI SP 2L BTL & 23040 & 64 & 19 & INGA CO 2L BOT & 8640 & 24 \\
\hline 6 & SEDAAP 2L REF & 29520 & 82 & 20 & $\begin{array}{l}\text { FORTUNE 1L } \\
\text { BOT }\end{array}$ & 33480 & 93 \\
\hline 7 & MADINA 5L JRG & 11520 & 32 & 21 & $\begin{array}{l}\text { ROSE BRAND 5L } \\
\text { JRG }\end{array}$ & 7560 & 21 \\
\hline 8 & FORTUNE 2L BOT & 25920 & 72 & 22 & SANIA 1L REF & 32760 & 91 \\
\hline 9 & BIMOLI 2L BOT & 21960 & 61 & 23 & $\begin{array}{l}\text { ROSE BRAND 2L } \\
\text { REF }\end{array}$ & 15840 & 44 \\
\hline 10 & BIMOLI SP 2LT REF & 23760 & 66 & 24 & $\begin{array}{l}\text { FORTUNE 2L } \\
\text { REF }\end{array}$ & 16920 & 47 \\
\hline 11 & FILMA 5L JRG & 8280 & 23 & 25 & $\begin{array}{l}\text { IKAN DORANG } \\
\text { SP 2L BTL }\end{array}$ & 7560 & 21 \\
\hline 12 & ROSE BRAND 1L REF & 44640 & 124 & 26 & SOVIA 2L REF & 14400 & 40 \\
\hline 13 & BIMOLI SP 1LT REF & 37080 & 103 & 27 & SUNCO 2L REF & 11880 & 33 \\
\hline 14 & SANIA 5L JRG & 7560 & 21 & 28 & SUNCO 1L REF & 23040 & 64 \\
\hline
\end{tabular}

Sumber: data Swalayan Mina, diolah 2017.

Data di atas merupakan data hasil perhari selama 1 tahun dengan 364 hari kerja. Data perhitungan kebutuhan barang dagangan untuk produk minyak goreng per hari digunakan untuk menentukan besarya kebutuhan minyak goreng selama masa lead time. 
c. Mengalikan lead time optimum dengan kebutuhan barang dagangan perhari

Lead time optimum yang dimaksud adalah lead time dengan frekuensi terbesar atau lead time yang paling sering terjadi dalam 30 kali pemesanan yaitu lead time 7 hari.

Tabel 9. Data kebutuhan minyak goreng selama lead time 7 hari

\begin{tabular}{|c|c|c|c|c|c|c|c|}
\hline No. & Nama Barang & $\begin{array}{l}\text { Kebutuhan } \\
\text { Perhari }\end{array}$ & $\begin{array}{l}\text { Kebutuhan } \\
\text { selama } \\
\text { lead time } \\
\end{array}$ & No. & Nama Barang & $\begin{array}{l}\text { Kebutuhan } \\
\text { Perhari }\end{array}$ & $\begin{array}{l}\text { Kebutuhan } \\
\text { selama } \\
\text { lead time } \\
\end{array}$ \\
\hline 1 & BIMOLI SP 5LT JRG & 71 & 497 & 15 & $\begin{array}{l}\text { IKAN DORANG } \\
\text { SP 5L BTL }\end{array}$ & 12 & 84 \\
\hline 2 & BIMOLI 5LT JRG & 51 & 357 & 16 & $\begin{array}{l}\text { BIMOLI SP 1L } \\
\text { BOT }\end{array}$ & 81 & 567 \\
\hline 3 & HEMART 5L JRG & 49 & 343 & 17 & SOVIA 5L JRG & 20 & 140 \\
\hline 4 & KUNCI MAS 2L REF & 80 & 560 & 18 & SANIA 2L REF & 54 & 378 \\
\hline 5 & BIMOLI SP 2L BTL & 64 & 448 & 19 & INGA CO 2L BOT & 24 & 168 \\
\hline 6 & SEDAAP 2L REF & 82 & 574 & 20 & $\begin{array}{l}\text { FORTUNE 1L } \\
\text { BOT }\end{array}$ & 93 & 651 \\
\hline 7 & MADINA 5L JRG & 32 & 224 & 21 & $\begin{array}{l}\text { ROSE BRAND 5L } \\
\text { JRG }\end{array}$ & 21 & 147 \\
\hline 8 & FORTUNE 2L BOT & 72 & 504 & 22 & SANIA 1L REF & 91 & 637 \\
\hline 9 & BIMOLI 2L BOT & 61 & 427 & 23 & $\begin{array}{l}\text { ROSE BRAND 2L } \\
\text { REF }\end{array}$ & 44 & 308 \\
\hline 10 & BIMOLI SP 2LT REF & 66 & 462 & 24 & $\begin{array}{l}\text { FORTUNE 2L } \\
\text { REF }\end{array}$ & 47 & 329 \\
\hline 11 & FILMA 5L JRG & 23 & 161 & 25 & $\begin{array}{l}\text { IKAN DORANG } \\
\text { SP 2L BTL }\end{array}$ & 21 & 147 \\
\hline 12 & ROSE BRAND 1L REF & 124 & 868 & 26 & SOVIA 2L REF & 40 & 280 \\
\hline 13 & BIMOLI SP 1LT REF & 103 & 721 & 27 & SUNCO 2L REF & 33 & 231 \\
\hline 14 & SANIA 5L JRG & 21 & 147 & 28 & SUNCO 1L REF & 64 & 448 \\
\hline
\end{tabular}

Sumber: data Swalayan Mina, diolah 2017

Tabel 9 merupakan hasil perhitungan kebutuhan barang dagangan minyak goreng selama lead time, yakni selama masa menunggu antara waktu pemesanan sampai barang dikirim dan sampai di gudang Swalayan Mina. Perhitungan kebutuhan selama lead time 7 hari merupakan salah satu komponen penentuan ROP selain besarnya safety stock.

d. Menentukan ROP dengan cara menambahkan hasil kali pada langkah c dengan besaran safety stock yang telah ditentukan pada tahap ke 2 .

Penentuan besaran ROP menggunakan rumus:

$$
\mathrm{ROP}=(\text { Lead Time } \mathrm{x} \text { Kebutuhan perhari })+\text { Safety Stock }
$$

Tabel 10. penentuan besaran ROP

\begin{tabular}{|c|c|c|c|c|c|c|c|c|c|}
\hline No. & Nama Barang & $\begin{array}{l}\text { Kebutuhan } \\
\text { selama } \\
\text { lead time }\end{array}$ & $\begin{array}{l}\text { Satey } \\
\text { Stock }\end{array}$ & ROP & No. & Nama Barang & $\begin{array}{l}\text { Kebutuhan } \\
\text { selama } \\
\text { lead time }\end{array}$ & $\begin{array}{l}\text { Safety } \\
\text { Stock }\end{array}$ & ROP \\
\hline 1 & $\begin{array}{l}\text { BIMOLI SP 5LT } \\
\text { JRG }\end{array}$ & 497 & 30 & 527 & 15 & $\begin{array}{l}\text { IKAN DORANG } \\
\text { SP 5L BTL }\end{array}$ & 84 & 21 & 105 \\
\hline 2 & BIMOLI 5LT JRG & 357 & 21 & 378 & 16 & $\begin{array}{l}\text { BIMOLI SP 1L } \\
\text { BOT }\end{array}$ & 567 & 24 & 591 \\
\hline 3 & HEMART 5L JRG & 343 & 48 & 391 & 17 & SOVIA 5L JRG & 140 & 29 & 169 \\
\hline 4 & $\begin{array}{l}\text { KUNCI MAS 2L } \\
\text { REF }\end{array}$ & 560 & 36 & 596 & 18 & SANIA 2L REF & 378 & 24 & 402 \\
\hline 5 & BIMOLI SP 2L BTL & 448 & 47 & 495 & 19 & INGA CO 2L BOT & 168 & 21 & 189 \\
\hline 6 & SEDAAP 2L REF & 574 & 415 & 989 & 20 & $\begin{array}{l}\text { FORTUNE 1L } \\
\text { BOT }\end{array}$ & 651 & 68 & 719 \\
\hline 7 & MADINA 5L JRG & 224 & 52 & 276 & 21 & $\begin{array}{l}\text { ROSE BRAND 5L } \\
\text { JRG }\end{array}$ & 147 & 13 & 160 \\
\hline
\end{tabular}


Purnomo dan Riani: Implementasi Kombinasi 3IC Tools Sebagai Penentu Optimasi...

\begin{tabular}{|c|c|c|c|c|c|c|c|c|c|}
\hline 8 & FORTUNE 2L BOT & 504 & 46 & 550 & 22 & SANIA 1L REF & 637 & 76 & 713 \\
\hline 9 & BIMOLI 2L BOT & 427 & 38 & 465 & 23 & $\begin{array}{l}\text { ROSE BRAND 2L } \\
\text { REF }\end{array}$ & 308 & 118 & 426 \\
\hline 10 & $\begin{array}{l}\text { BIMOLI SP 2LT } \\
\text { REF }\end{array}$ & 462 & 48 & 510 & 24 & FORTUNE 2L REF & 329 & 40 & 369 \\
\hline 11 & FILMA 5L JRG & 161 & 37 & 198 & 25 & $\begin{array}{l}\text { IKAN DORANG } \\
\text { SP 2L BTL }\end{array}$ & 147 & 31 & 178 \\
\hline 12 & $\begin{array}{l}\text { ROSE BRAND 1L } \\
\text { REF }\end{array}$ & 868 & 190 & 1058 & 26 & SOVIA 2L REF & 280 & 43 & 323 \\
\hline 13 & $\begin{array}{l}\text { BIMOLI SP 1LT } \\
\text { REF }\end{array}$ & 721 & 267 & 988 & 27 & SUNCO 2L REF & 231 & 47 & 278 \\
\hline 14 & SANIA 5L JRG & 147 & 46 & 193 & 28 & SUNCO 1L REF & 448 & 45 & 493 \\
\hline
\end{tabular}

Sumber: data Swalayan Mina, diolah 2017.

dari table diatas dapat ditentukan besaran ROP, yakni suatu kondisi level persediaan pada saat perusahaan harus melakukan pemesanan ulang. Reorder Point dalam konteks manajemen persediaan sangat penting karena menjadi salah satu metodo dalam mengambiil keputusan terkait status persediaan dalam mencapai target efektifitas dan efisiensi. Status ROP paling banyak ada pada produk minyak goreng merek Rosebrand 1ltr Ref, sedangkan paling kecil pada produk merek Ikan Dorang SP 1L Btl.

\section{PENUTUP}

Simpulan. 1) Penerapan metode ABC dalam menentukan kelas persediaan menunjukkan terdapat 28 item minyak goreng yang masuk pada kelas A, sebanyak 21 item masuk pada kelas B, sedangkan sisanya sebanyak 31 item masuk pada kelas C; 2) Penentuan safety stock paling banyak adalah pada item Sedaap 2L Ref sebanyak 251,77 dibulatkan menjadi 252 buah; 3) Reoder Point paling banyak adalah pada minyak goreng merek Rosebrand Kemasan Reffil 1 Liter.

Bersadarkan kesimpulan tersebut, penulis merekomendasikan kepada pengelola Swalayan Mina, Bahwa 1). penentuan kelas untuk setiap item persediaan sangatlah penting, karena pengambil kebijakan dapat mengetahu dengan pasti item barang apa saja yang harus tersedia karena kebutuhan permintaan yang besar dan harga yang mahal. 2). Diperkuat dengan penentuan safety stock agar tidak terjadi kehabisan persediaan atau out of stock. 3). Metode Reorder Point merupakan pelengkap dalam pengendalian persediaan barang dagangan di Swalayan Mina, dengan mengetahui besaran ROP dalam setiap produk minyak goreng yang memiliki nilai persediaan mencapai $70 \%$, maka Swalayan Mina dapat memesan tepat waktu dan saat pesanan datang, persediaan minyak goreng digudang sudah tepat pada status safety stock.

\section{DAFTAR RUJUKAN}

Assauri, S. (1999) Manajemen Produksi Dan Operasi (Edisi Revi). Jakarta: Lembaga Penerbitan Fakultas Ekonomi Universitas Indonesia.

Dewi, I. Y. (2010) Analisis pengendalian persediaan bahan baku kertas cd roll with safety stock pada $C V$. Adinugraha.

Hadi, L. D. dan R. (2004) Manajemen logistik.

Heizer, J., \& Render, B. (2014) Operations Management. Sustainability and Supply Chain Management. In Operations Management. Sustainability and Supply Chain Management (p. 255).

Herjanto, E. (2008) Manajemen Operasi (Edisi Keti). Jakarta: Gramedia. 
Ishak, A. (2010) Manajemen Operasi (Edisi Pert). Yogyakarta: Graha Ilmu.

Martani, D., Siregar, S. V., Wardhani, R., Farahmita, A., Tanujaya, E., \& Hidayat, T. (2012) Akuntansi Keuangan Menengah Berbasis PSAK (Jilid 1). Jakarta: PT. Salemba Empat.

Rangkuti, F. (2007) anajemen persediaan: aplikasi dibidang bisnis; pendekatan praktis dengan lebih 40 kasus berikut pembahasannya. Jakarta: PT. Raja Grafindo Persada.

Sugiono, A. (2009) Manajemen Keuangan untuk Praktisi Keuangan. Jakarta: Gramedia Widiasarana Indonesia. 